\title{
Las tolas perdidas de Caranqui y su contexto histórico y regional
}

\author{
Tamara L. Bray* y José Echeverría A.**
}

\section{RESUMEN}

El sitio arqueológico de Caranqui comprende uno de los múltiples Centros de montículos



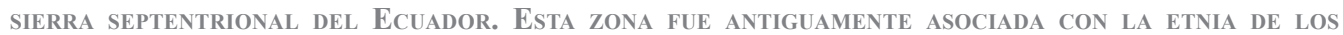
Caranqui-Cayambe durante el Período Tardío precolombino. Alguna vez numerosos, aunque AHORA DESAPARECIENDO RÁPIDAMENTE, LOS ENORMES TERRAPLENES CULTURALES REPRESENTAN UN LEGADO SUMAMENTE IMPORTANTE DEL PASAdO Y UNA VENTANA ÚNICA DENTRO DE LA VIDA COTIDIANA, POLÍtiCA, Y CEREMONIAL DE LOS IMBABUREÑOS AUTÓCTONOS. EN ESTE ARTíCULO, REVISAMOS BREVEMENTE LOS DATOS etNohistóricos Pertenecientes a los Caranqui-CaYambe, Proveemos una aCtualización Sobre los RESULTADOS DE INVESTIGACIONES ARQUEOLÓGICAS RECIENTES PERTENECIENTES A LAS TOLAS DE LA REGIÓN, Y DOCUMENTAMOS - EN BASE A LA MEMORIA E HISTORIA ORAL DE LOS HABITANTES, ADEMÁS DE LOS VESTIGIOS arqueológicos - las tolas PERdidas de la ParRoQuia de CARANQui.

Palabras claves: montículos monumentales - paisajes precolombinos - Caranqui-Cayambe - Andes SEPTENTRIONALES - ECUAdOR - PÉRDIDA DE PATRIMONIO CULTURAL.

\section{Abstract}

The archaeological site of Caranqui constitutes one of the numerous Centers of monumental EARTHWORKS THAT CHARACTERIZED THE PRE-COLUMBIAN LANDSCAPE OF THE PROVINCE OF IMBABURA IN THE

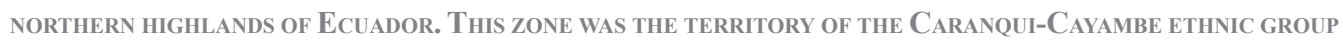
DURING THE LATE PRE-COLUMbian PERIOD. The ENORMOUS CULTURAL MOUNDS OR TOLAS, FORMERLY FOUND THROUGHOUT THIS REGION BUT FAST DISAPPEARING, CONSTITUTE AN IMPORTANT MATERIAL LEGACY OF THE PAST AND A UNIQUE WINDOW INTO THE DAILY, POLITICAL, AND CEREMONIAL LIVES OF THE ORIGINAL INHABITANTS OF THIS REGION. IN THIS ARTICLE, WE BRIEFLY REVIEW THE ETHNOHISTORIC DATA PERTAINING TO THE CARANQUICAYAMBE; PROVIDE AN UPDATE ON THE RESULTS OF RECENT RESEARCH ON THE MOUND SITES OF THE REGION; AND DOCUMENT ON THE BASIS OF ORAL HISTORY, COLLECTIVE MEMORY, AND ARCHAEOLOGICAL VESTIGES, THE "LOST TOLAS" OF THE VILLAGE OF CARANQUI.

Keywords: platform mounds - Pre-Columbian landscapes - Caranqui-Cayambe - northern Andes ECUADOR - LOSS OF CULTURAL HERITAGE.

* Tamara L. Bray, Profesora, Departamento de Antropología, Wayne State University, Detroit, Michigan. En 2014 Investigadora-Prometeo con el GADM, Cantón de Ibarra, y Universidad Técnica del Norte, Ecuador. Correo electrónico: t.bray@wayne.edu.

** José Echeverría Almeida, consultor independiente, Otavalo, Ecuador. Correo electrónico: joecheve50@yahoo.com. 
L a parroquia urbana de Caranqui está ubicada a tres kilómetros al sur de la ciudad de Ibarra y cinco kilómetros al suroeste de la históricamente memorable laguna de Yaguarcocha. El pueblo de Caranqui, de 15.500 personas (INEC, 2010), ha sido por siglos reconocido como el centro antiguo del cantón Ibarra y sus alrededores. Datos arqueológicos recientes del área central del pueblo proveen evidencia de una ocupación que se extiende desde hace al menos 2000 años en el pasado (Bray y Echeverría, 2014). En este artículo, revisamos brevemente los datos etnohistóricos pertenecientes a los Caranqui. Proveemos una actualización sobre los resultados de investigaciones arqueológicas recientes pertenecientes a las tolas en la sierra septentrional, y documentamos - en base a la memoria e historia oral de los parroquianos, además de los vestigios arqueológicos - las "tolas perdidas" de Caranqui.

El sitio arqueológico de Caranqui comprende uno de los múltiples centros de montículos monumentales que caracterizan el paisaje precolombino de la provincia de Imbabura (foto 1). Alguna vez numerosos, aunque ahora desapareciendo año tras año, estos enormes edificios culturales que en una manera imitan las colinas naturales, representan un legado sumamente importante del pasado y una ventana única dentro de la vida cotidiana, política, y ceremonial de los imbabureños autóctonos. Las pocas estructuras monumentales que quedan en la parroquia Caranqui y en la provincia de Imbabura en general, son testigos materiales del alto nivel de organización social lograda en esta región y la capacidad física e intelectual de la población precolombina imbabureña (Bray, 2003; Lumbreras, 1990; Oberem, 1981; Salomon, 1980).

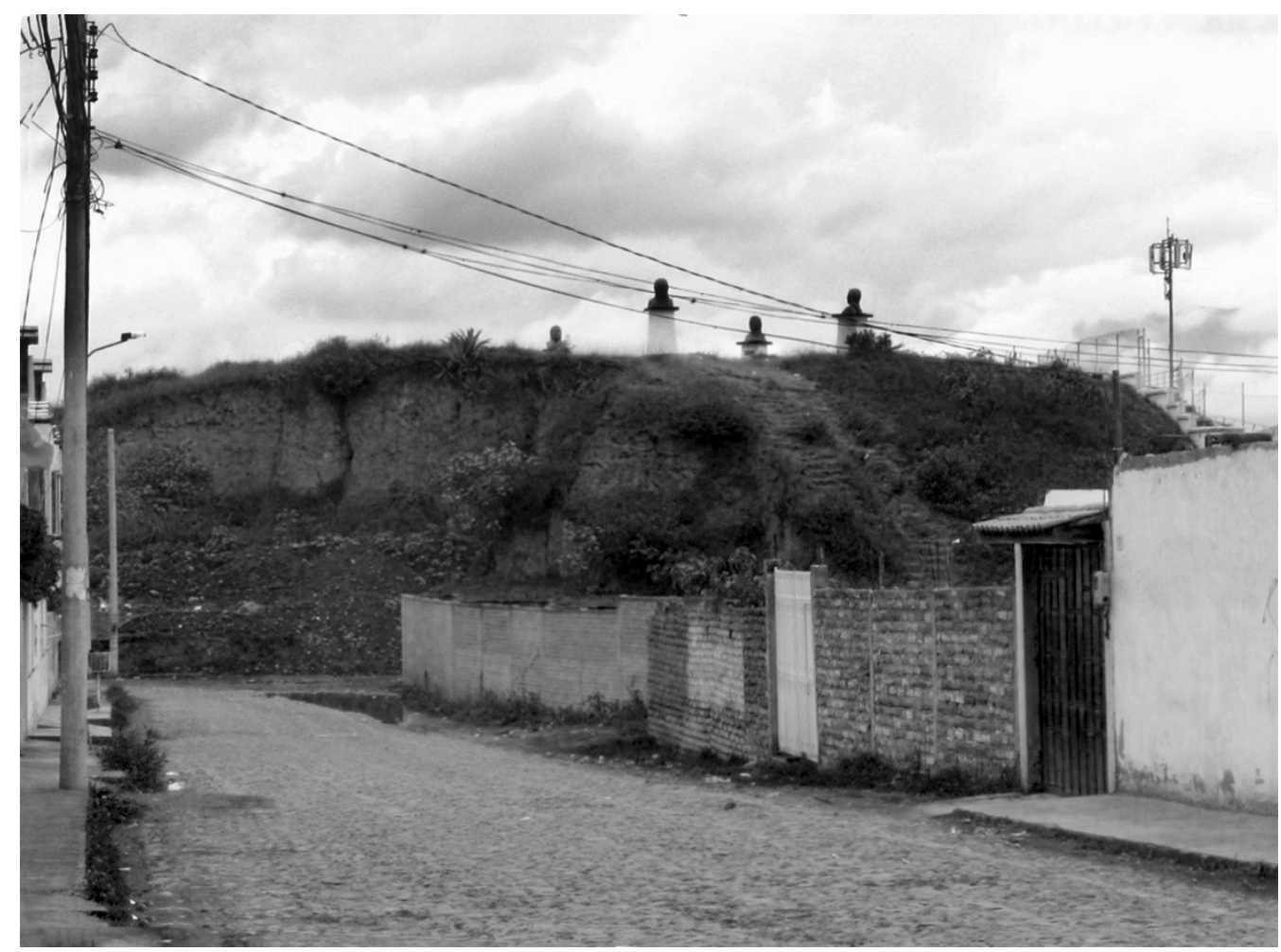

Foto 1. Foto de tola "Emapa” en la esquina noroeste del centro del pueblo de Caranqui, vista desde la Calle los Incas en el lado este del montículo. Foto: Tamara Bray. 
La verdad es que hay muy pocas culturas y pocos lugares en las Américas que exhiben este tipo de restos monumentales como los que forman parte del paisaje cultural del Pais Caranqui ${ }^{1}$, aunque el Ecuador parece haber tenido más que su justa parte. Por ejemplo, se puede ver en varios sectores del Litoral del Ecuador terraplenes monumentales, aun si no son exactamente iguales a los que tenemos en el Pais Caranqui, como en el caso de Real Alto (Marcos, 1988), en La Tolita (Uhle, 1927; Valdez, 1987), en la alta cuenca del río Guayas (Guillaume-Gentil, 1998), y en Palenque (Porras, 1983); en la parte Occidental de la provincia de Imbabura y del norte y noroccidente de la provincia de Pichincha (Jara, 2007; Lippi, 1998); y en la ceja de montaña Oriental (Porras, 1961; 1975). En otras partes del hemisferio, como en la costa del Perú, el valle central de México, y las llanuras de inundación del río Mississippi en Norteamérica son otras de las pocas regiones que también exhibieron terraplenes en una escala monumental.

Tomando en cuenta este antecedente, podemos decir que el paisaje antiguo cultural de la provincia de Imbabura representa algo especial en la evolución de las culturas indígenas americanas. Con esta consideración, y en base a la discusión sobre lo que fue el Caranqui antiguo, queremos enfatizar en la importancia del esfuerzo mancomunado y concertado para conservar los escasos monumentos que quedan, tanto por su valor histórico y arqueológico, como educativo y turístico. Aunque estos edificios culturales continúan en la memoria colectiva y en la toponimia local, su presencia material tiene un impacto que no puede ser reproducido solo por palabras o recuerdos. Por estas razones, insistimos en la imperiosa necesidad de conservar las pocas tolas que sobreviven en el Pais Caranqui. Hacemos un llamado a los GADs municipales y gobiernos provinciales, para que cumplan los artículos relacionados con el Patrimonio Natural y Cultural establecidos en el COOTAD y publicados en el Registro Oficial № 514 del 3 de junio de 2015.

\section{Las tolas en la historia precolombina de la Sierra septentrional}

La palabra "tola" no pertenece al léxico español ni al quichua, parece más bien ser un vocablo de la población aborigen de la sierra septentrional del Ecuador, aceptado en la lengua española de la Audiencia de Quito desde muy temprano (Caillavet, 1983: 10). Dentro de los documentos tempranos de los siglos XVI y XVII, esta palabra parece haber sido utilizada para referirse a lomas naturales o culturales, aunque más comúnmente en el segundo sentido (Ibíd.). Para Federico González Suárez, obispo de Ibarra a principios del siglo XX, erudito en este tipo de vestigios monumentales y en la influencia del grupo Chibcha en el norte del actual Ecuador, el vocablo "tola" provendría de tocvaa o tocva de la lengua Caribe, y significaría "hueco de paz" (toc: paz y va: hueco) (Ibíd., 2002 [1902]:64). Según R. Lippi (comunicación personal, 2014), "tola" proviene de la familia lingüística Barbacoa y es también una palabra en la lengua de los Tsáchila que significa "loma no natural." Hoy en día, se usa "tola" más que nada en la región de Imbabura para referirse a los montículos hemisféricos o cuadriláteros hechos a mano que son elementos muy visibles del paisaje cultural.

Estos montículos se encuentran en grupos discretos a través de la provincia de Imbabura, al extremo norte de la provincia de Pichincha y al extremo sur de la provincia del Carchi (Gondard y López, 1983). Su distribución coincide con los límites de lo que conocemos como el Pais Caranqui y sirve para definir físicamente la extensión de la etnia Caranqui-Cayambe. Hasta ahora, en el Pais Caranqui, se han identificado y comprobado por visita 66 sitios con tolas cuadrangulares (28 de los cuales contienen tolas con rampa) (Athens, 2003: 5; ver también Athens y Osborn, 1974; Gondard y López, 1983). La gran mayoría de éstas están ubicadas en elevaciones entre 2000-3000 metros sobre el nivel del mar, la altura óptima para la producción

1 El Pais Caranqui, según lo definido por Jijón y Caamaño (1952: 343), se refiere a la región norte de los Andes históricamente asociado con la poderosa confederación de las naciones Caranqui y Cayambe. En términos geopolíticos modernos, esta región abarca los sectores de las tierras altas de Imbabura y Pichincha provincias del norte, Ecuador (Bray, 1992). 
del maíz. El número total de las tolas en cada sitio varía mucho. El sitio más grande conocido es el de Zuleta ubicado en la zona sureste del volcán Imbabura que una vez contó con unas 148 tolas en un área de 340 hectáreas (Athens, 2003: 34). Entre los demás, el número de montículos varían entre unos seis o siete hasta sesenta (Ibíd., 1978; 2003).

\section{Las formas de las tolas}

Las tolas exhiben una de dos formas básicas, redondas en forma hemisférica o cuadrangular y en forma de pirámide truncada (foto 2). Los dos tipos exhiben un gran rango de tamaños. Los montículos hemisféricos pequeños pueden tener desde dos a seis metros de diámetro y uno a dos metros de altura. Generalmente se piensa que estas tolas son montículos funerarios (Jijón y Caamaño, 1914, 1952: 342; Oberem y Hartmann, 1981: 50-53; Osborn y Athens, 1974: 5). Las tolas hemisféricas grandes pueden tener hasta 90 metros de diámetro y alcanzan 10 a 12 metros de altura, como las que existen en Atuntaqui (Athens, 2003: 63-66). La basura doméstica y los pisos encontrados encima de algunas de éstas sugieren que funcionaron como montículos de casas (Jijón y Caamaño, 1920: 47; Athens y Osborn, 1974: 7-8).

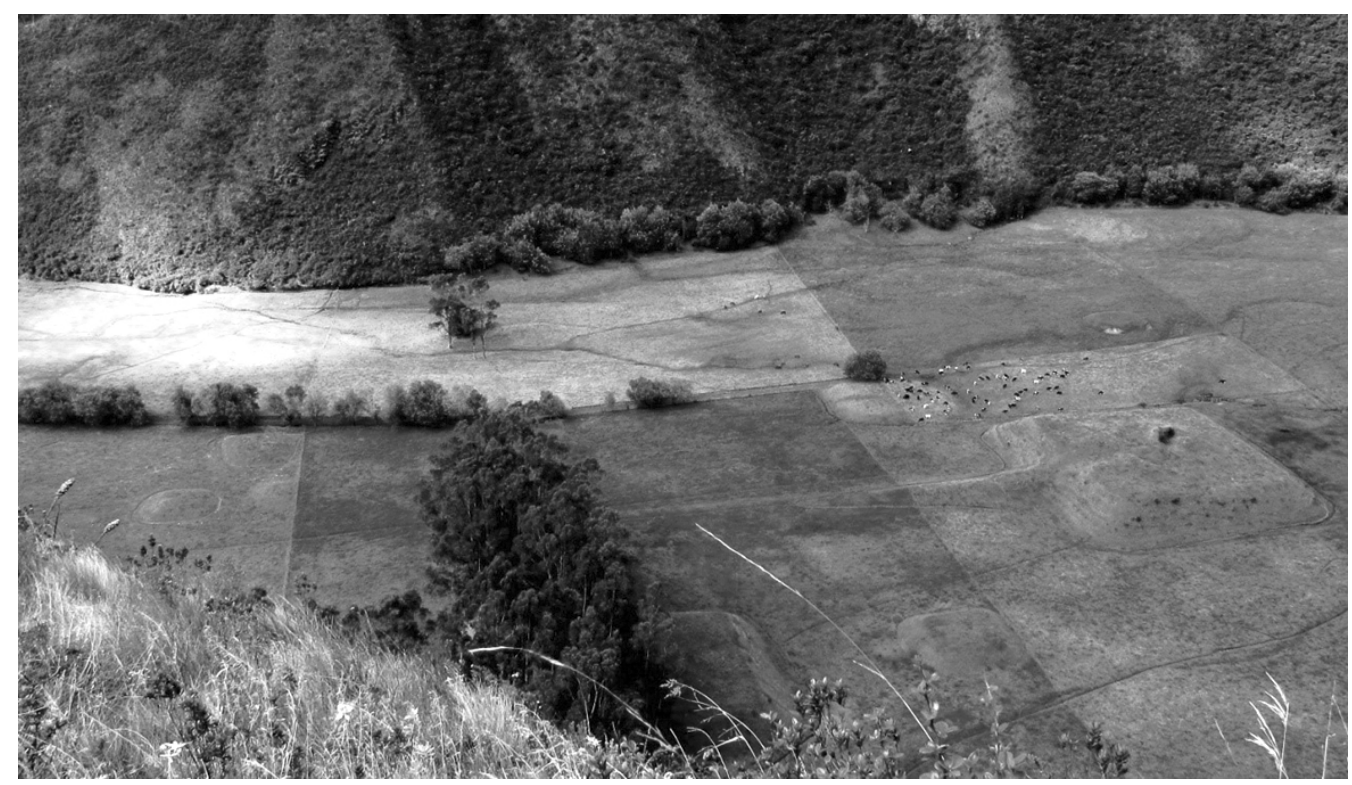

Foto 2. Conjunto de tolas, ambos redondos y cuadrilaterales en el sito de Zuleta. Foto: Tamara Bray.

Las tolas cuadrangulares están subdivididas según si exhiben una rampa inclinada en un lado o no. Hasta ahora, no se ha reconocido ninguna diferencia funcional entre las tolas piramidales con rampa y sin rampa (Athens, 1980: 147-165; Oberem, 1981a), aunque también han sido muy poco estudiadas por los arqueólogos formales. Más bien, parece que las tolas con rampa sirvieron como un rasgo de distinción y un diagnóstico temporal del período tardío precolombino (ver abajo). Ambos tipos fueron construidos en una escala monumental. El rango de tamaños medidos de las bases de las pirámides varía desde 400 metros cuadrados hasta más de 10.000 metros cuadrados y alturas entre 10 a 15 metros. La más grande registrada en el Pais Caranqui es la inmensa Orozca Tola en Andrade Marín (cantón Antonio Ante), que mide 207 x $150 \mathrm{~m}$. por al menos $25 \mathrm{~m}$. de altura (Athens, 2003: 63). En el pueblo de Caranqui, el montículo denominado "Tola Emapa" es la más grande que queda (foto 1). Tiene una forma cuadrangular y aunque ha sido parcialmente destruida en tres de cuatro lados, todavía exhibe aproximadamente 46 x $46 \mathrm{~m}$. en su cima y unos 9-10 m. de altura. 


\section{Función de las tolas}

Tanto los montículos hemisféricos grandes como los cuadrangulares parecen haber servido como plataformas para estructuras grandes con techos. Las investigaciones arqueológicas emprendidas en las tolas monumentales en varios sitios, incluyendo Urcuquí, Cochasquí, Socapampa, Otavalo, Pinsaquí, Gualimán y Zuleta, han expuesto pisos de plano circular de barro quemado con evidencia de moldes de postes en la cima de estos edificios. Típicamente asociado con los pisos circulares, es un elemento inusual que consta de una cavidad rectangular alargada y escalonada de barro quemado que se encuentra moldeada dentro del piso (Athens, 1980: 147-161; 2012; Echeverría, 2009; Jijón y Caamaño, 1914: 297; Oberem, 1969: 322) (foto 3). Los mejores preservados de estos elementos, que varían en largo desde uno a nueve metros, frecuentemente poseen huecos de tullpa rumis (piedras de fogón) arreglados en una disposición triangular alrededor del perímetro del fogón; de vez en cuando estas piedras cónicas se han hallado in situ en excavaciones (Athens, 2012:,3; Oberem, 1981a: 6467; Wurster, 1981). Estos elementos largos y únicos han sido interpretados como fogones, posiblemente utilizados en la preparación de comida y bebida para festines especiales o para ofrendas rituales (Athens, 2003; Oberem, 1981a: 66; Wurster, 1981: 98-100). Sin embargo, en las estructuras similares encontradas en El Tablón, Yahuarcocha, no se encontró vestigios de ceniza o de carbón, como para inferir su uso como fogón (Echeverría, 2009). Encima de las tolas grandes hemisféricas han sido encontrados pisos circulares de barro idénticos (e.g, Athens, 1980: 147, 154) y también en las superficies no modificadas entre montículos en el sitio de Cochasquí (Oberem, 1981a: 65-66).

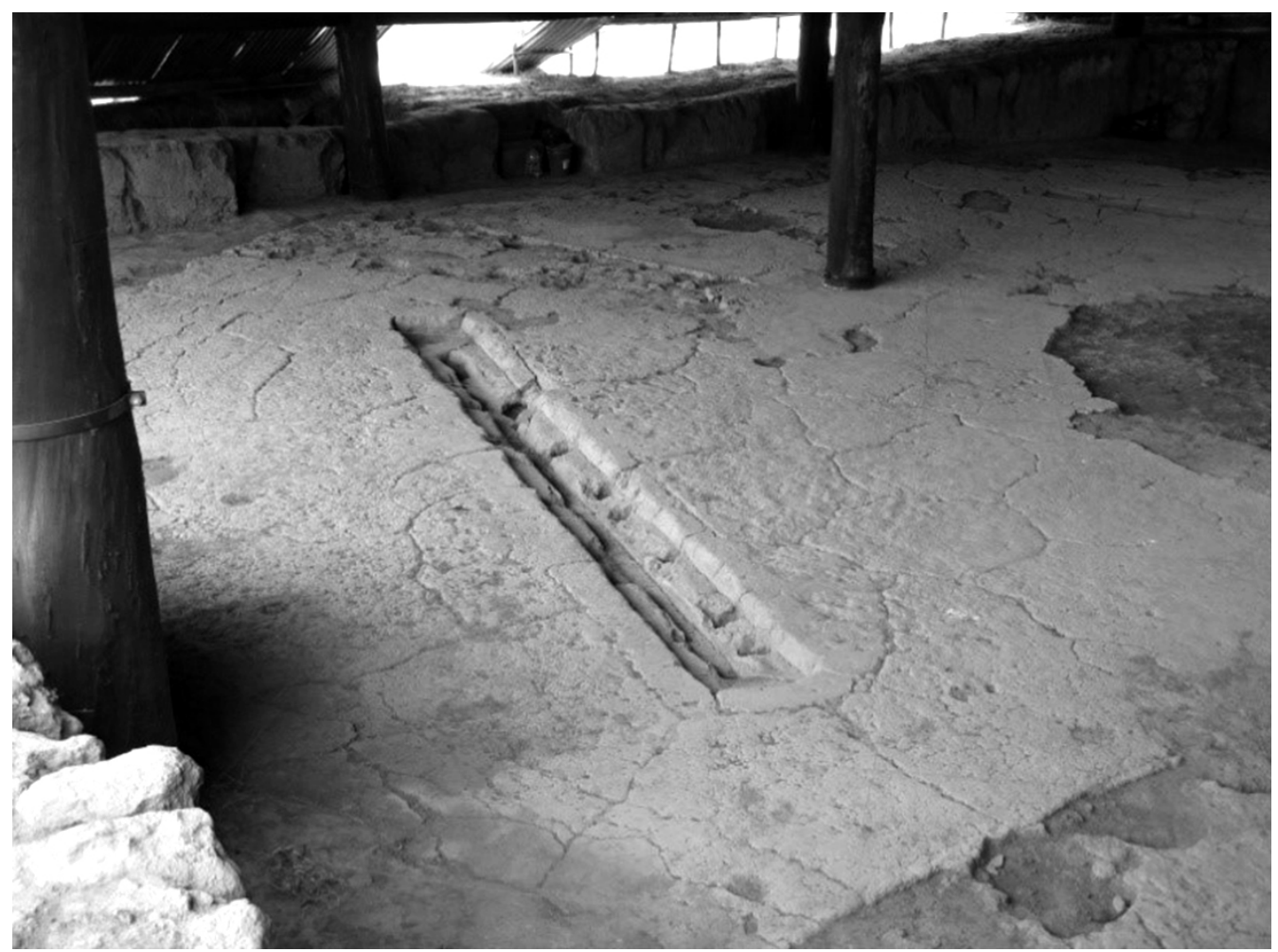

Foto 3. Cavidad rectangular alargada en un piso circular de arcilla quemado encima de Montículo E en el sitio de Cochasquí. Foto: Tamara Bray. 
Los artefactos encontrados en las excavaciones de las tolas cuadrangulares también indican una función residencial para estos edificios, no está muy claro si éstos fueron espacios residenciales permanentes u ocupados periódicamente. La cerámica asociada con estos sitios es típicamente de estilo local tosca denominada Caranqui, con formas comunes consistentes en un ánfora grande de cuerpo alargado y un cuenco poco profundo. Meyers (1981) refiere a éstas dos formas como ánforas y sartenes, respectivamente (también Athens, 1978; Bray, 2003). El ánfora, que frecuentemente exhibe decoración roja (herrumbre) sobre ante (color natural de la vasija) es ubicua en los asentamientos del Período Tardío (1250 a 1550 d.C.) de la sierra norte, principalmente en los sitios con tolas cuadrangulares (Echeverría, 1995: 263-264) (figura 1). La morfología del ánfora sugiere que se usó para almacenaje de líquidos; en el contexto del Pais Caranqui específicamente, se ha propuesto que fueron importantes en la producción y almacenaje de chicha (Athens, 2003; Bray, 1995; 2003). Las cantidades de ánforas encontradas en asociación con los montículos cuadrangulares, su tratamiento decorativo especial, y su gran tamaño - en muchos casos un metro de alto o más - apuntan a la posibilidad de que las casas redondas encima de los montículos grandes eran los espacios destinados a fiestas colectivas, que involucran el consumo de grandes cantidades de chicha y comida. Excavaciones recientes en el sitio de Zuleta, por ejemplo, han producido casi 20 enormes ánforas con bocas de unos 50 a $65 \mathrm{~cm}$. de diámetro, encontradas en asociación con un piso circular encima del Montículo EE (Athens, 2012) (foto 4).

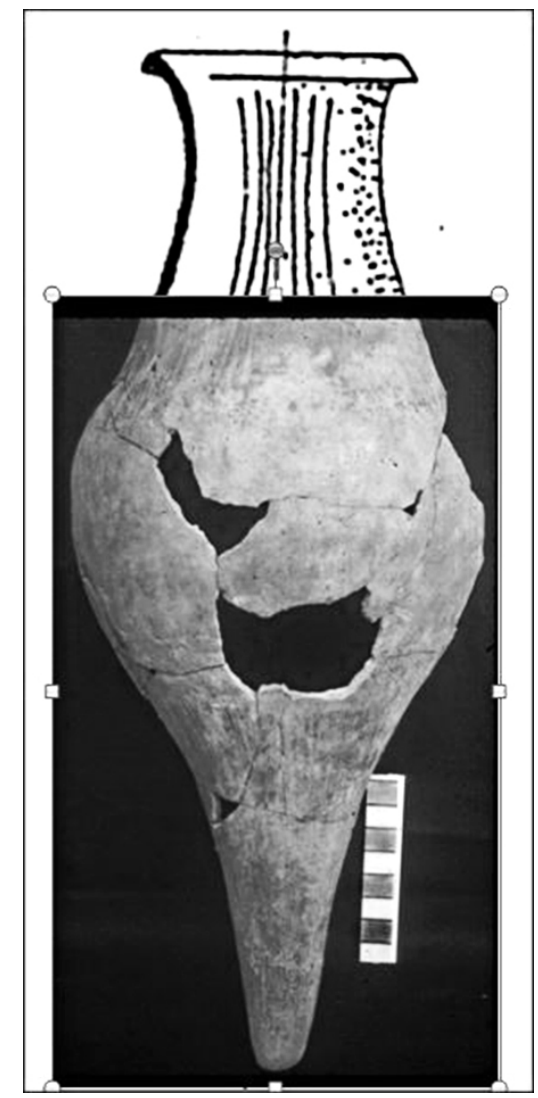

Figura 1. Cerámica diagnostica del periodo tardío en el Pais Caranqui: un ánfora grande con engobe rojo del Pueblo de Caranqui (Museo Atahualpa, Caranqui). 


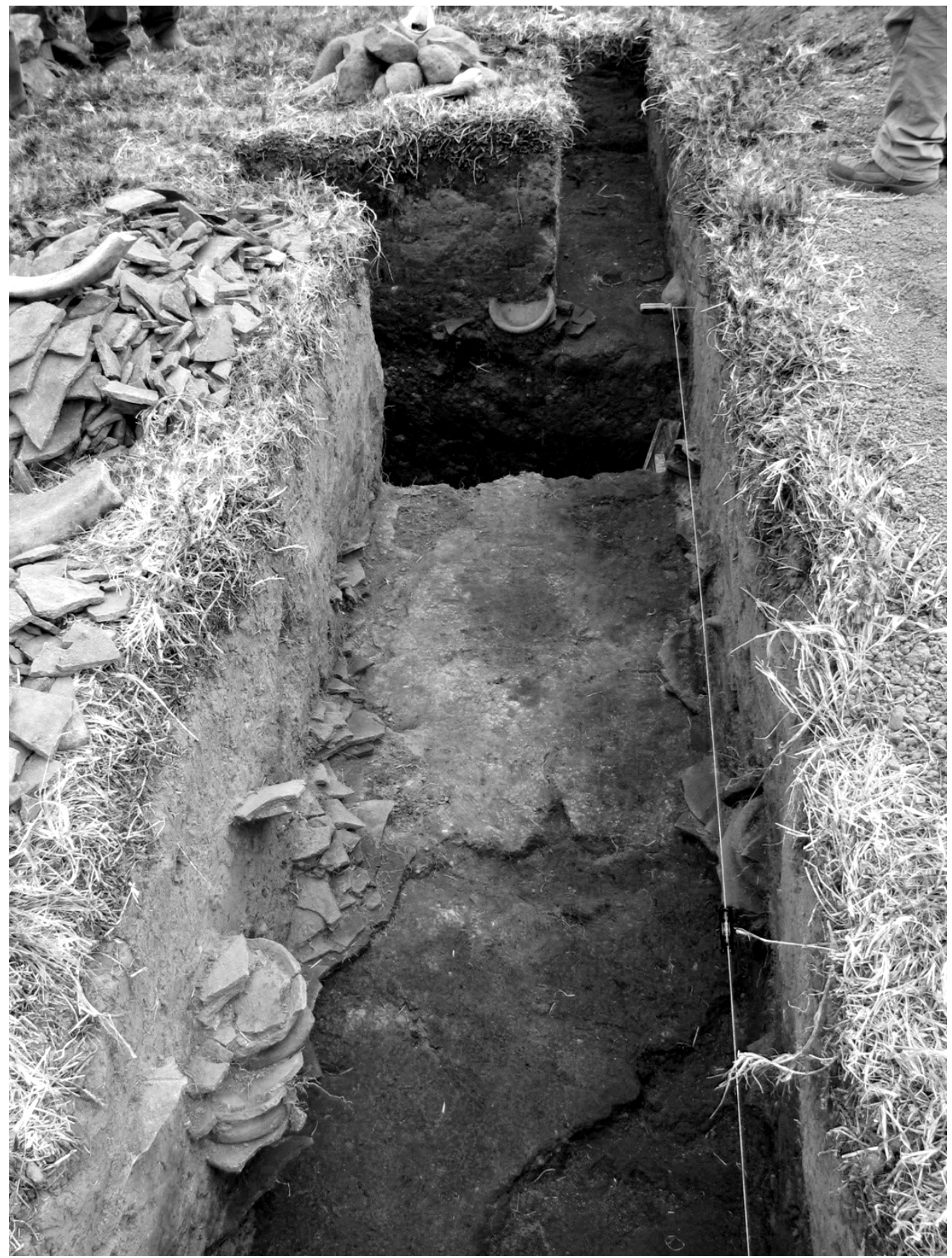

Foto 4. Excavación de una trinchera encima de tola EE en el sitio de Zuleta en 2009 mostrando las CANTIDADES DE RECIPIENTES ENORMES ENCONTRADOS EN EL CORTE ESTRATIGRÁFICO; NÓTESE LOS TIESTOS EN ambos perfiles del corte y el piso de arcilla quemada al fondo. Foto: cortesía de J. Stephen Athens. 
Junto con el ánfora y el cuenco poco profundo, hay dos formas más de vasijas cerámicas muy comunes en los asentamientos de los sitos-tola del Período Tardío (1250 a 1550 d.C.). Uno es el comal (denominación mexicana) conocido con varios nombres locales como tiesto, chayana, cayana, o kallana, consistente en un disco grande, plano o ligeramente cóncavo, delgado, útil para cocer las tortillas de maíz, los granos de maíz, el cacao, etc., que es un objeto todavía utilizado hoy en día, especialmente en el sector rural, campesino, tanto indígena como mestizo. La otra forma es la olla trípode, utilizada para la cocción de alimentos. Las cuatro formas descritas: ánfora, cuenco, comal y olla trípode son diagnósticas, por su popularidad, del Período Tardío (Bray, 1995; Echeverría, 1995: 253-316).

Los otros tipos de artefactos encontrados en estos sitios, como huesos de animales (cuy, llama, venado, conejo, y perro), manos y metates para moler, lascas de obsidiana, y ocasionalmente, instrumentos musicales como flautas de hueso y pitos de cerámica, también indican una función residencial y la importancia central de actividades culinarias y festines (Athens, 1978; Bray, 2003; Jijón y Caamaño, 1914; Oberem, 1981b).

Además de servir como plataformas para residencias cacicales, los terraplenes monumentales del Pais Caranqui también han sido considerados frecuentemente como áreas predilectas para funciones religiosas o ceremoniales - probablemente, debido más que nada a sus grandes dimensiones (Athens, 1980: 142; Jijón y Caamaño, 1920: 47; 1952: 315, 349; Oberem, 1969: 322; 1981: 66; Wurster, 1981: 98-100). Estas dos funciones no son necesariamente excluyentes entre sí.

En la jurisdicción de Otavalo, varias iglesias coloniales se erigieron en la parte superior de las tolas - una señal convincente de su carácter sagrado, mientras algunas tolas existentes seguían siendo utilizadas por los pueblos indígenas para las ceremonias religiosas hasta mediados de los años 1900 (Caillavet, 2000 [1981]: 38). Al mismo tiempo, un señor de Ynambi en su testimonio de 1592 declara que era dueño de tierras en Puenachi donde su padre "tenía casa y colcas y una tola donde tenía su casa" (Caillavet, 1983: 10).

Informes oficiales de la región del siglo XVI tardío, anotan que "las casas construidas por los hombres y sus caciques fueron como una iglesia" y que "eso era donde los caciques hicieron su presencia y vinieron juntos para beber" (Anónimo, 1965 [1573]: 226). Otro ejemplo excepcional es la presencia de una capilla católica y cementerio en la superficie de la tola ubicada en el ingreso al actual pueblo de San Pablo, cantón Otavalo, provincia de Imbabura. Tal como anota Salomon (1986: 126) en ausencia de evidencias de estructuras religiosas especiales, "es probable que la casa del jefe haya sido el lugar de la acción ceremonial". La suma de evidencias sugiere que en el Pais Caranqui, los sitios tolas se asociaron con los cementerios ancestrales y probablemente sirvieron como centros de concentración periódica de los miembros de la comunidad dispersa, con fines sociales y ceremoniales.

\section{Cronología de las tolas}

Los montículos cuadrangulares con rampa, junto con las ánforas con pintura roja, son diagnósticos del Periodo Tardío en la sierra septentrional (Athens, 1978: 125). Este periodo está definido como la época inmediatamente anterior a la conquista incaica, empezando aproximadamente AD 1250, durando unos 250-275 años, y terminando con la derrota definitiva de los Caranquis en la batalla de Yaguarcocha circa AD 1520 (Bray y Echeverría, 2014). Un resumen de las fechas radiocarbónicas disponibles para los montículos con rampas en la región se presenta en la tabla 1.

Las tolas cuadrangulares sin rampas parecen anteceder a las que exhiben este rasgo, con fechas desde AD 975-1250 (Athens, 1978: 133-134; Oberem, 1981b: 249-251). Esta hipótesis ha sido apoyada recientemente mediante un análisis de la distribución geográfica de las tolas, en el que se observó una tendencia hacia la agrupación entre los sitios con tolas sin rampa (Yanchar, 2013: 67). Las formas de terraplenes más antigua en el Pais Caranqui son 
los montículos hemisféricos. Las pocas fechas que hay para este tipo de tola, que viene del Monticulo "x" en Cochasquí (Oberem, 1981b: 249-251) y Montículos 18 y 19 de Socapamba (Athens, 1978: 133-134), indican que su construcción era una práctica establecida en el Pais Caranqui por AD 650-700 (Athens, 1978: 125-126; también Pazmiño, 2014) y que su uso continuo, en varios casos, fue contemporáneas con las formas cuadrangulares.

\section{TABLA 1.}

Fechas radiocarbónicas (C14) de montículos cuadrangulares con rampa en la Sierra norte.

\begin{tabular}{|c|c|c|c|c|}
\hline Sitio & Contexto & $\begin{array}{c}\text { Edad } \\
\text { Convencional BP }\end{array}$ & Fecha & Fuente \\
\hline Atuntaqui & $\begin{array}{l}\text { Rasgo asociada con la parte } \\
\text { inferior del montículo }\end{array}$ & $519 \pm 46$ & $\begin{array}{l}\text { AD } 1406-1438 \\
\quad(\mathrm{CAL})\end{array}$ & (Athens, 2003: 67) \\
\hline Cochasquí & $\begin{array}{l}\text { Pirámide E con rampa, pos. } \\
\text { tumba }\end{array}$ & $930+/-i$ & $\mathrm{AD} 1020$ & (Oberem, 1981b: 249) \\
\hline Cochasquí & Pirámide E con rampa & $720+/-20$ & AD 1200-1240 & (Oberem, 1981b: 249) \\
\hline Cochasquí & Pirámide $\mathrm{K}$ con rampa & $700+/-100$ & AD $1150-1350$ & (Oberem, 1981b: 251) \\
\hline Cochasquí & $\begin{array}{c}\text { Pirámide E con rampa, pos. } \\
\text { tumba }\end{array}$ & $690+/-50$ & AD $1210-1310$ & (Oberem, 1981b: 249) \\
\hline Cochasquí & $\begin{array}{c}\text { Pirámide E con rampa, piso } \\
\text { quemado }\end{array}$ & $475+/-65$ & AD $1410-1540$ & (Oberem, 1981b: 251) \\
\hline Cochasquí & $\begin{array}{c}\text { Pirámide E con rampa, piso } \\
\text { quemado }\end{array}$ & $465+/-50$ & AD $1435-1535$ & (Oberem, 1981b: 251) \\
\hline Cochasquí & $\begin{array}{c}\text { Pirámide E con rampa, piso } \\
\text { quemado }\end{array}$ & $390+/-50$ & AD $1510-1610$ & (Oberem, 1981b: 251) \\
\hline Otavalo & Montículo 4, corte 2, 79 cmbs. & $450 \mathrm{AP}+/-140$ & AD 1360-1640 & (Athens, 1980: 135) \\
\hline $\begin{array}{c}\text { La } \\
\text { Libertad }\end{array}$ & $\begin{array}{l}\text { Cerca de la parte superior de } \\
\text { rampa del montículo }\end{array}$ & $389+/-45$ & $\begin{array}{c}\text { AD } 1433-1642 \\
\text { (CAL) }\end{array}$ & (Athens, 2003: 67) \\
\hline Puntiachil & $\begin{array}{l}\text { Montículo principal con } \\
\text { rampa }\end{array}$ & $430+/-60$ & $\begin{array}{c}\text { AD } 1410-1640 \\
(\mathrm{CAL})\end{array}$ & (Cordero, 1996: 208 ) \\
\hline Puntiachil & $\begin{array}{l}\text { Montículo principal con } \\
\text { rampa }\end{array}$ & $340+/-70$ & $\begin{array}{c}\text { AD } 1435-1670 \\
(\mathrm{CAL})\end{array}$ & (Cordero, 1996: 208) \\
\hline Pinsaqui & Montículo 1 con rampa & $360+/-65$ & AD $1525-1655$ & (Athens, 1978: 133) \\
\hline Socapamba & $\begin{array}{l}\text { Montículo } 21 \text { con rampa, } \\
\text { asoc. con piso }\end{array}$ & $600+/-60$ & AD $1310-1430$ & (Athens, 1978: 134) \\
\hline Socapamba & $\begin{array}{l}\text { Montículo } 15 \text { con rampa, } \\
\text { asoc. con piso }\end{array}$ & $480+/-70$ & AD $1400-1540$ & (Athens, 1978: 134) \\
\hline Zuleta & $\begin{array}{l}\text { Montículo EE con rampa; } \\
\text { asoc. con piso quemado }\end{array}$ & (no reportado) & AD 1294-1391 & (Athens, 2012: 1) \\
\hline
\end{tabular}


Un estudio reciente de patrones regionales de asentamientos en el Pais Caranqui sugiere que posiblemente había una jerarquía entre los sitios que contenían tolas con rampa a base del tamaño real de estos sitios y el número de tolas por sitio (Yanchar, 2013: 51-52). De los 27 sitios documentados por Athens (1978; 2003: 33-38), 20 contienen entre 1-25 montículos, 6 tenían entre 30-66 montículos, y uno -Zuleta- registra 148 tolas- más que el doble del sitio más densamente construido que es el de Gualimán cerca de Intag. Así la mayoría de sitios (75\%) exhiben menos que 25 montículos, mientras que un porcentaje más pequeño $(25 \%)$ manifiesta una cantidad de tales estructuras significativamente más numeroso, sugiriendo la posibilidad de una jerarquía regional de dos niveles. Nosotros pensamos que esto puede responder también a la densidad poblacional y a la facilidad de consecución de recursos que pudo tener cada curacazgo o cada unidad política y económicamente independiente.

Mirando a la relación entre estos sitios, utilizando estadísticas espaciales involucrando varias tipos de análisis de "nearest-neighbors," Yanchar (Ibíd., 54-55) determinó que los sitios con tolas con rampas tienden hacia un modelo de distribución disperso, con una distancia media de $6.6 \mathrm{~km}$. entre cada sitio. Asumiendo que los sitios con tolas con rampas fueron centros de poder político y asentamientos de las elites, este patrón de distribución disperso sugiere, en cambio, una ausencia de relaciones jerárquicas entre ellos, un intento de lograr una maximización de control territorial y la posibilidad de relaciones hostiles entre estos centros políticos-religiosos (Ibíd.: 54-55). Como se discute previamente (Bray, 2008), este patrón bien puede reflejar un sistema de complejidad regional mejor caracterizado como heterárquica más que de jerárquica en su naturaleza.

Cuando se analiza todos los sitios con montículos en el Pais Caranqui, se encontró un patrón estadísticamente significativo de agrupación a una distancia media menor de $3 \mathrm{~km}$. entre cada sitio (Ibíd.). Esto sugiere que los rasgos más tempranos del paisaje cultural, por ejemplo, las tolas hemisféricas, pudieron haber actuado en el tiempo como atractivos, dibujando rasgos identitarios regionales para ellos y creando sus propios centros de gravedad resultando en el aumento demográfico y económico. Estos aumentos en el poder y la riqueza se registraron a través de la construcción de montículos cada vez más grandes y nuevos tipos de obras de trabajos colectivos aun más intensivos resultando en enormes terraplenes como las tolas cuadrangulares con rampa.

La distribución de los sitios con tolas también revela que había una división sub-regional entre norte y sur en el Pais Caranqui, donde en la mitad norte se encuentran sitios con tolas más grandes y numerosas que en la mitad sur (Larraín Barros, 1980; Yanchar, 2013: 67-68). La división entre estas dos zonas comprende una línea imaginaria este-oeste que pasa entre el lago San Pablo y la laguna Mojanda, dejando los sitios grandes de Atuntaqui y Zuleta al lado norte, y los de Cochasquí y Puntiachil (Cayambe) al lado sur, entre otros (mapa 1). Entre las dos zonas, hay una faja de aproximadamente $10 \mathrm{~km}$. de ancho que sigue la misma orientación que está vacía de asentamientos con tolas; podemos pensar que esta banda fue una "área de amortiguamiento", que antiguamente formaba la división entre la población Caranqui al norte y la población Cayambe al sur.

Esta división sub-regional está evidenciada también por el reciente análisis de las arcillas utilizadas en la producción de las cerámicas del Período Tardío en los sitios con tolas en el Pais Caranqui (Minc et al., 2014; Yanchar, 2013: 101-107). Los resultados indican que la cerámica asociada con los sitios, tanto en el norte como en el sur, fueron producidos con arcillas locales disponibles. Mientras que la cerámica de fabricación local se intercambió mínimamente entre los sitios con tolas dentro de cada subregión, los vasos producidos en el norte no se encontraron en la mitad sur del territorio, y vice versa (Ibíd.). Estos estudios confirman la naturaleza semiautónoma de los diversos pequeños curacazgos que comprendía el Pais Caranqui; sin embargo, estas organizaciones políticas mantienen una clara identidad étnica compartida como se refleja en los patrones de asentamiento y la cultura material. La distribución espacial de sitios sugiere la probabilidad de una significante división regional entre las partes norte y sur. Adicionalmente, la configuración y tamaños de los sitios en el sector norte nos lleva a proponer una división subregional entre los territorios en el lado este y oeste del volcán Imbabura. 


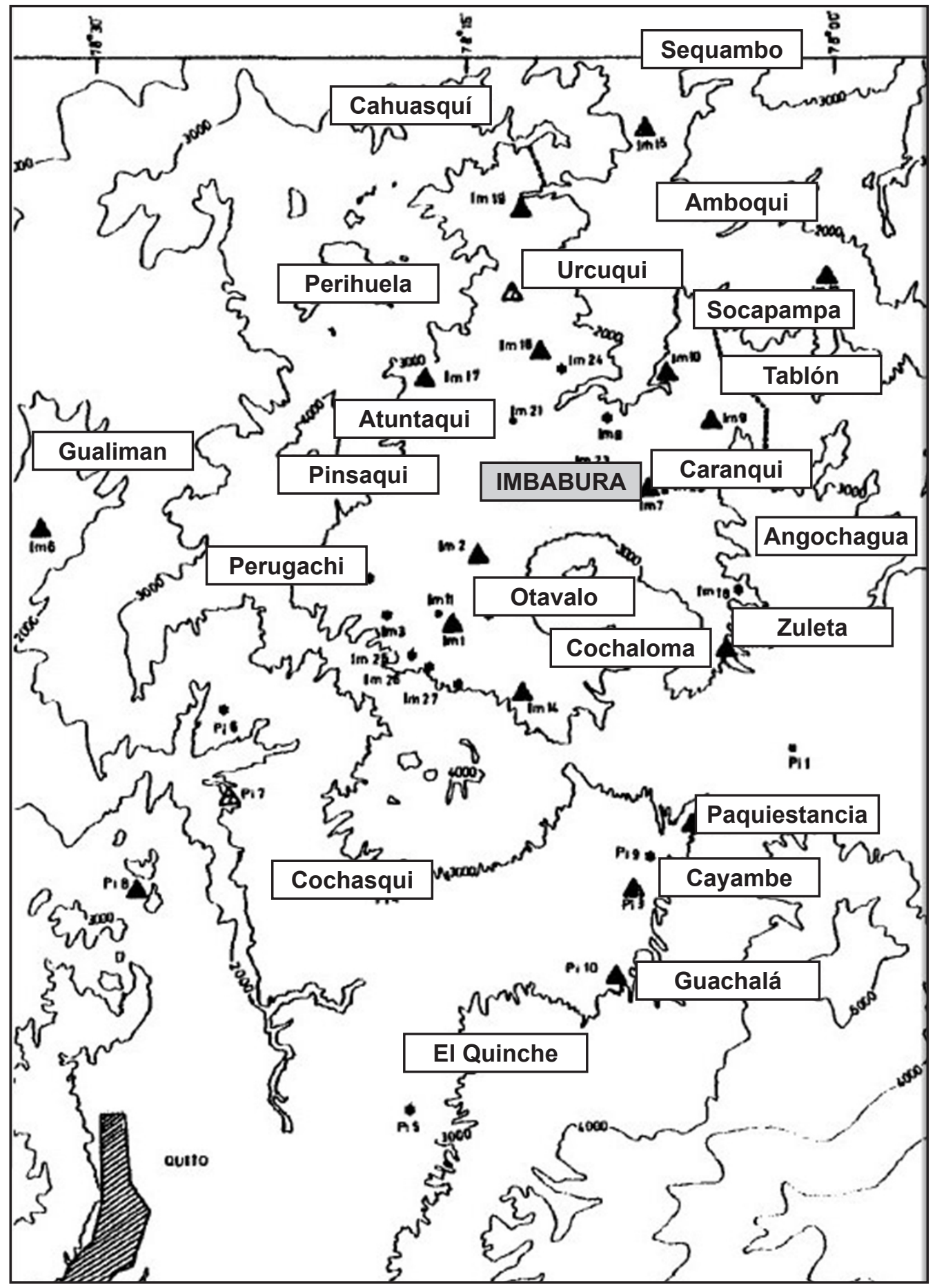

Mapa 1. Pais Caranqui indicando sitios con tolas PRincipales y la división del territorio en






\section{El Curacazgo de Caranqui}

La suma de la información arqueológica y etnohistórica sugiere que en el Pais Caranqui había tres señoríos principales centrados en el volcán Tayta Imbabura, hacia finales del Período Tardío (ver también Ontaneda, 1998: 14). Por conveniencia, referimos a estos con los nombres de los pueblos históricos más conocidos en cada sector (mapa 2). Primero, abarcando el área al oeste del Tayta Imbabura, estaba el Curacazgo de Otavalo, que incluyó los sitios con tolas circundantes, la laguna San Pablo en la parte sur-el más grande de estos, Cochaloma (cerca del pueblo de González Suarez) —y, en la parte norte, el sitio más impresionante de Atuntaqui con sus inmensas tolas cuadrangulares. Al sur de los Otavalos estaba el Curacazgo de Cayambe, con el sitio más importante de este sector aparentemente siendo el asociado con la Hacienda Paquiestancia y no con el mismo Cayambe de hoy, incluye sitios al oeste como Cochasqui, además, al sur, en la hoya del Guayllabamba y el sector de Pifo y El Quinche. Finalmente, ocupando la zona oriental del volcán Imbabura y el valle longitudinal del río Tahuando, estaba el Curacazgo de Caranqui, que es el enfoque del presente estudio.

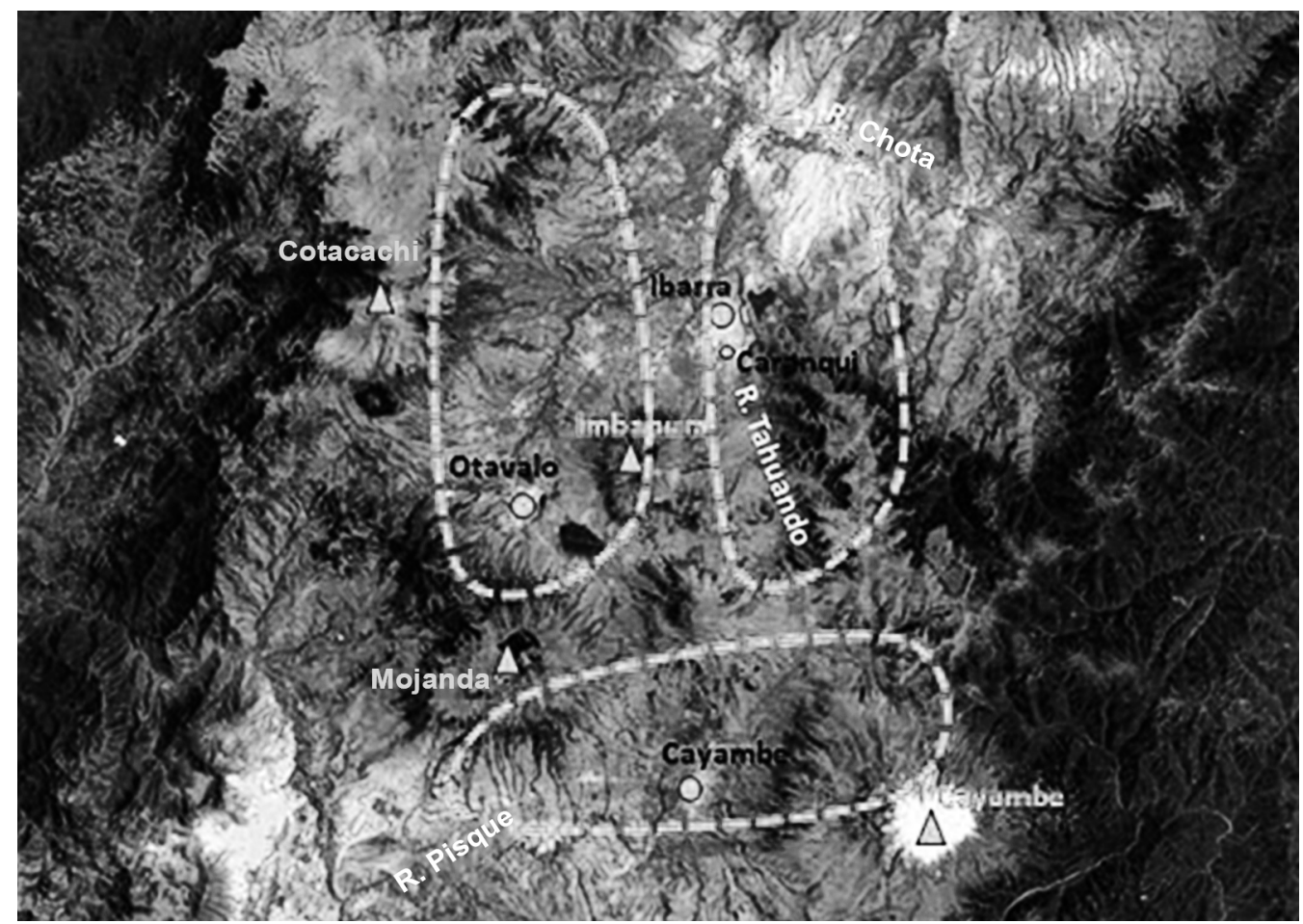

Mapa 2. País Caranqui indicando los límites de los tres Curacazgos PRincipales en la Región perteneciendo a los Otavalos, los Cayambes, y los Caranquis.

Cada uno de estos señoríos mantenía acceso a una variedad de pisos ecológicos en la forma discutida por Oberem (1978) como "microverticalidad"2. Uno de los pisos climáticos de más importancia constituyeron los valles cálidos en donde se producía algodón, coca, ají, frutos subtropicales como el aguacate y otros productos de gran demanda en la economía cotidiana y festiva de los Caranquis y etnias vecinas. Los caciques de Otavalo mantenían determinados derechos

2 Ver, por ejemplo, el testamento del cacique de Otavalo escrito en 1609, don Alonso Maldonado, que repartió chacaras de varias zonas entre sus cinco hijos (Caillavet, 1982). 
a usufructuar de los terrenos ubicados en los valles calientes de los ríos Mira y Guayllabamba, mientras que los de Cayambe estuvieron vinculados con la hoya de Guayllabamba, y los de Caranqui manejaron tierras en los valles del Chota y Ambuquí (Ramon, 1987: 22-39).

Con respecto específicamente al Curacazgo de Caranqui, parece que los señores étnicos controlaban una serie de zonas ecológicas desde las alturas de los páramos de Angochagua a 3800 m.s.n.m., hasta los valles de los ríos Ambuquí y Chota-Mira a 1600 m.s.n.m. El acceso a los productos de estas zonas y el control sobre su distribución constituyó una fuente de poder fundamental para los curacas de esta región (Salomon, 1986, 1990).

Deducimos los límites del territorio del Curacazgo Caranqui en base de las divisiones de tierras hechos durante la época Colonial, varios testimonios de curacas locales, y la distribución espacial de los sitios con tolas cuadrilaterales en este sector (ver también Moreno, 2007; Ontaneda, 1998). Un indicador importante de los linderos de los curacazgos prehispánicos fue el repartimiento del territorio en encomiendas en la época colonial (Moreno, 2007: 125). La de Caranqui en 1582 comprendía los pueblos de Caranqui mismo, San Antonio, Chapi y Pimampiro (Paz Ponce de León, 1965 [1582]: 240). La integridad de este conjunto en la época precolombina está apoyada por la declaración del cacique de Cayambe, Fabian Puento en 1645, que su abuelo materno, don Cristóbal Caranguelin Puento, era "casique [sic] y señor que fue de todo el repartimiento de los pueblos de Carangue, San Antonio y valle de Ambuquí...” (citado en Ramón, 1987: 67). También, ventas de tierras transaccionadas por varios principales de Caranqui durante la primera parte del siglo XVII que involucraron terrenos en las zonas cálidas de Conrraqui y Ambuquí, provee evidencia adicional del control sobre estas tierras por los señores antiguos de Caranqui (AHBC/I, 1604, 1624, 1626, 1642).

A manera de hipótesis, proponemos que el corazón del Curacazgo Caranqui fue el valle longitudinal del río Tahuando, en el que se observa aún en la actualidad una distribución densa de tolas, especialmente en el cauce superior, incluyendo los sitios de Zuleta, Angochagua y Cochicaranqui, cubriendo una distancia linear de unos $8 \mathrm{~km}$., e incorporando al menos unos 180 montículos monumentales a lo largo de este sector situados entre 2700-3000 m.s.n.m. (Athens, 1978; 2003; 2012; Muñoz y Bray, s/f; Currie, 2001) (mapa 3). Estos asentamientos tienen que ver también con el control del agua, aspecto insinuado por Knapp (1992) y Echeverría (1986) y que requiere una investigación más intensiva.

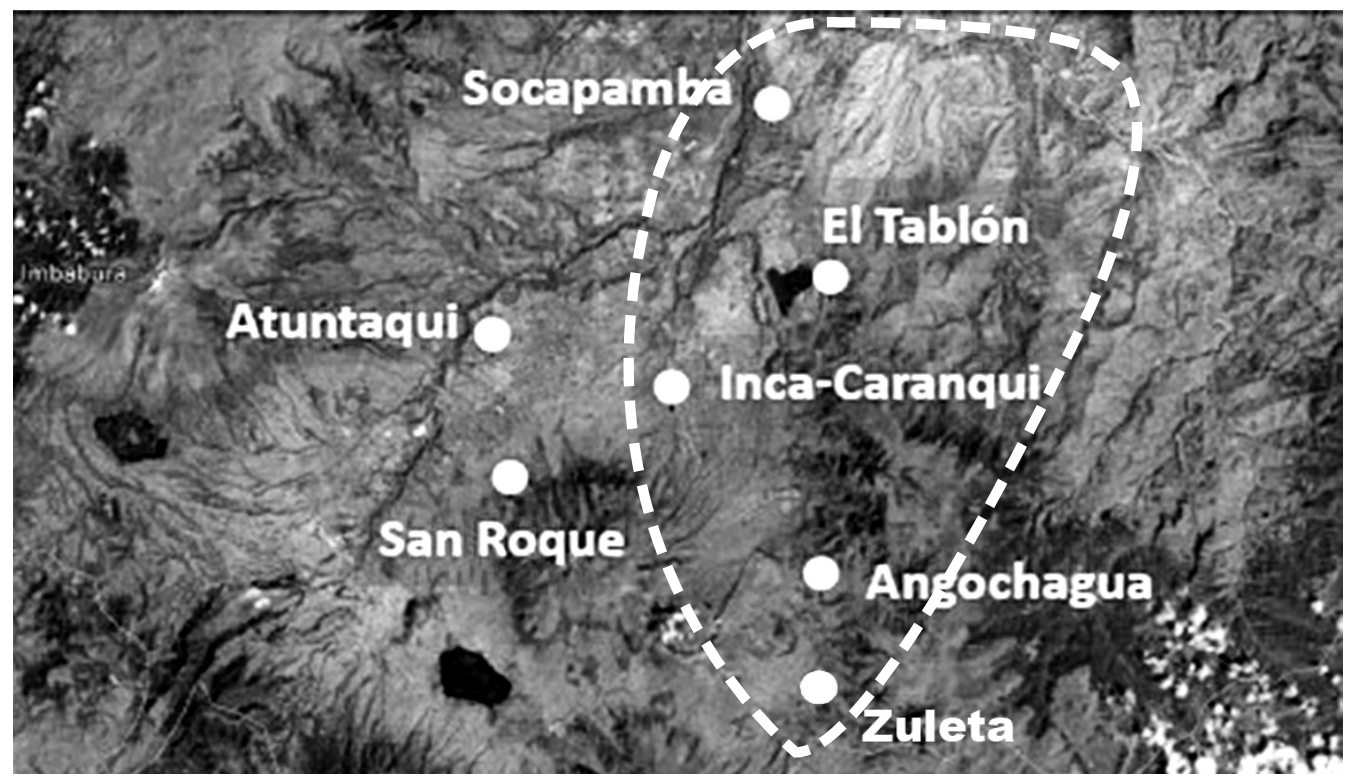

Mapa 3. Curacazgo de Caranqui. 
Aproximadamente $8 \mathrm{~km}$. más abajo al norte, a 2300 m.s.n.m., se encuentra el sitio de Caranqui que una vez contó con al menos 11 tolas, y que también llegó a ser el asentamiento más importante del imperio Inca en el extremo septentrional del Tawantinsuyu — probablemente debido a su ubicación estratégica (ver Bray y Echeverría, 2014). Unos $4 \mathrm{~km}$. más al NNE está el sitio arqueológico conocido como El Tablón, ubicado en el lado oriental de la laguna de Yaguarcocha, con 11 tolas todavía bien conservadas, una de los cuales exhibe una rampa (Echeverría, 2009). Unos pocos kilómetros al NNO se halla el sitio de Socapampa, el segundo más grande dentro del Curacazgo Caranqui, con unos 60 montículos (redondos y cuadrangulares) que desafortunadamente han sido fuertemente impactados por el desarrollo urbano y turístico descontrolado (Athens, 1978; 2003). Siguiendo abajo a las tierras subtropicales del valle ChotaMira hay varios sitios con tolas, incluyendo Tumbatú, Ambuquí, y Pimampiro (Athens, 1980: 262; Echeverría y Uribe, 1995: 45-148; Gondard y López, 1983) que muy probablemente fueron comprendidos dentro del ámbito del Curacazgo Caranqui.

En lo que sigue, nos concentramos en el sitio de Caranqui mismo, ubicado en la zona intermedia del Curacazgo Caranqui entre el cauce superior del río Tahuando y las tierras bajas del Ambuquí y el Chota a 2280 m.s.n.m. El sitio de Caranqui ha sido el enfoque de nuestras investigaciones arqueológicas desde el año 2007. Mientras que probablemente no fue el sitio más importante en la configuración territorial preincaica del Curacazgo Caranqui, llego a ser así en la época proto-histórica, por el papel que tenía este sitio en la historia. Por la destrucción que han sufrido sus tolas en los últimos 50 años, y para conservar algo de la memoria del Caranqui original, ofrecemos abajo una reconstrucción del sitio aborigen en base de la historia oral y los datos arqueológicos.

\section{Las tolas de Caranqui}

En una prospección regional conducida a mediados de los años 70 del siglo pasado, Athens (1978: 272) registró 11 tolas adyacentes al pueblo de Caranqui-redondas y cuadrangulares - y sugirió que un trabajo más intensivo en la zona probablemente revelaría montículos adicionales ${ }^{3}$. Regresando en el año 2001 para verificar y ampliar sus previos estudios, este investigador anotó la presencia de solo siete tolas en Caranqui, esta vez cinco redondas y dos cuadrangulares, escribiendo que la más grande (la "Tola Emapa") tenía un tamaño de 90 x 100m. x 10 metros de altura (Ibíd., 2003: 33, 43) (foto 5a). Hoy en día, de estas tolas anteriormente registradas en la parroquia Caranqui, tenemos solo los restos de la Tola Emapa, que mide casi la mitad de lo que fue hace 13 años (ver foto 1), y unos remanentes muy pequeños de unas pocas otras. Todo lo demás de estos restos monumentales representando el patrimonio cultural de la región y el país sufrieron el impacto ignominioso de ser convertidos en ladrillos por empresas pequeñas descontroladas y sin consciencia (foto $5 b$ ).

En base de un estudio de fotos aéreas y mapas antiguos, más entrevistas con personas mayores de la parroquia, ha sido posible inferir la existencia y ubicación anterior de unas 17 tolas asociadas con lo que hoy es la parroquia de Caranqui cubriendo un área de unas 70 hectáreas. Con respecto a las entrevistas, éstas se llevaron a cabo a lo largo de varios años, en relación con el Proyecto Arqueológico Inca-Caranqui (Bray y Echeverría, 2010; 2014), que fue centrada en el corazón de la parroquia urbana de Caranqui. Al vivir y trabajar en Caranqui desde 2008 a 2014, pudimos familiarizarnos con los residentes de esta parroquia y conversar informalmente con la gente de mayor edad y con sus descendientes sobre varios aspectos de vestigios de los antiguos Caranquis. También, como vivíamos dentro de la comunidad, tuvimos la oportunidad de constatar directamente en el campo los lugares donde pudieron haber existido los montículos artificiales, o las tolas de memoria, con la gente misma.

3 El número de código del sitio en el sistema de Athens (1978) es IM-07; en el sistema de Gondard y López, (1983), el sitio de Caranqui es registrado como No. I-082. 

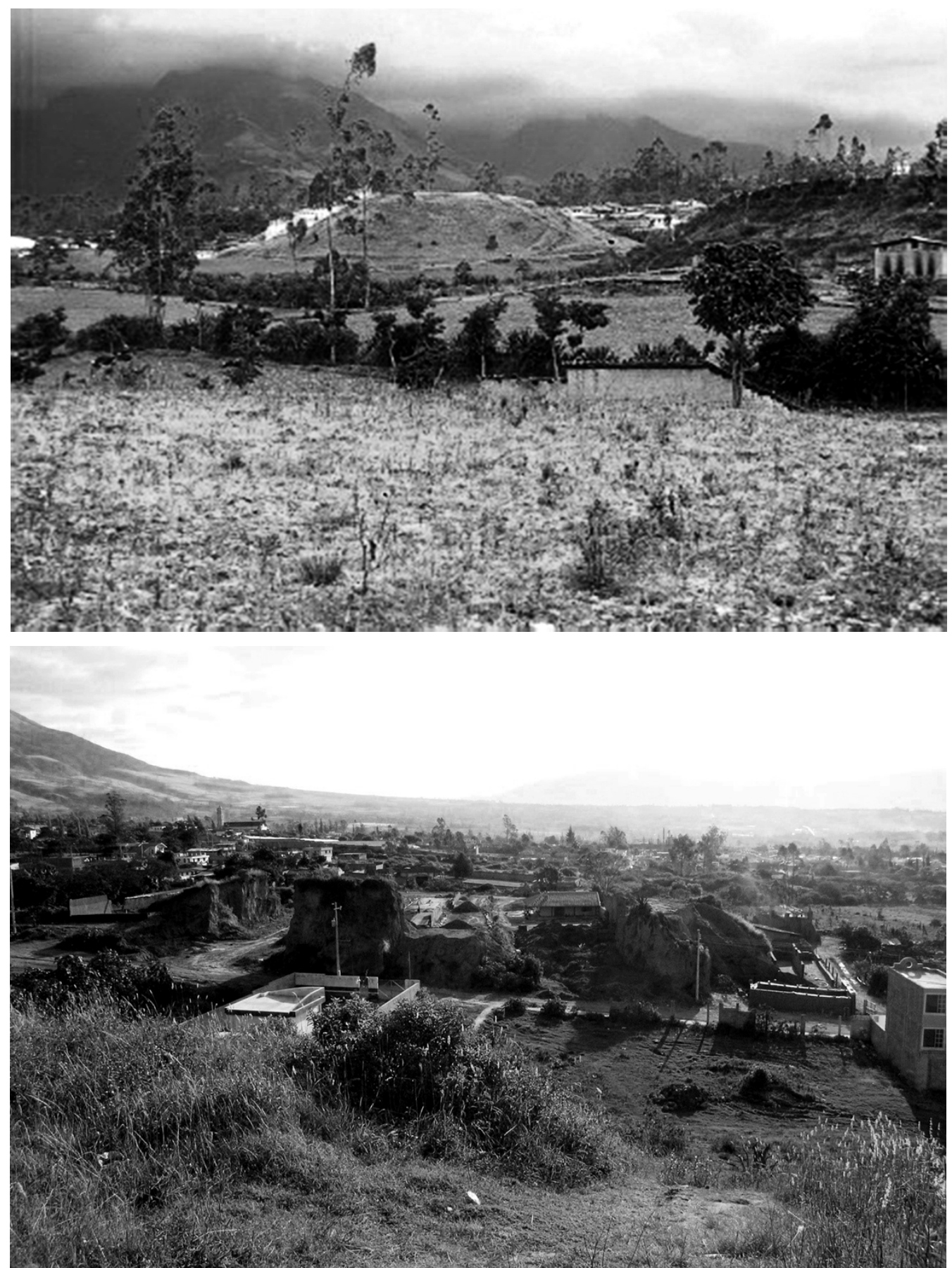

Fotos 5. Dos visitas de tolas cerca del centro del pueblo de Caranqui, (a) sacado en 1976 mostrando la Tola Emapa con las estatuas del lado Derecho de la foto y una tola grande a su lado oeste. Cortesía DE J.Stephen Athens; (B) SACAdo en 2008 mostrando la destrucción CASI COMPleta de la tola AL Lado OESTE DEBIDO A SU USO PARA LA MANUFACTURA DE LADRILLOS - NÓTESE EL HORNO DE LADRILLOS EN OPERACIÓN EN EL LADO DERECHO DE LA FOTO; HOY DÍA ESTA TOLA ESTÁ COMPLETAMENTE DESAPARECIDA. Foto: TAMARA BRAY. 
Tomando las coordenadas de las tolas conocidas por tradición oral, o sea las "tolas de memoria," hemos hecho una reconstrucción de la configuración de los montículos que una vez comprendieron el sitio antiguo de Caranqui (mapa 4). La información sobre estas "tolas perdidas" de Caranqui está recopilada en la tabla 2. Esta cantidad de montículos, junto con el tamaño enorme de la todavía existente Tola Emapa, indica que Caranqui fue un sitio de medio rango dentro del curacazgo del mismo nombre. Ubicada a una distancia intermedia entre la concentración densa de tolas en la vecindad de Cochicaranqui y el cauce superior del Tahuando, y los sitios grandes de Socapamba y del valle del río Chota. El de Caranqui probablemente juega un papel importante en la vinculación de los diferentes pisos ecológicos que comprendían el Curacazgo y en el tránsito de gente y bienes entre las varias zonas.

\section{Tabla 2: Inventario de las tolas de Caranqui en base de la historia oral y la Arqueología.}

\begin{tabular}{|c|c|c|c|c|c|}
\hline N. & $\begin{array}{l}\text { Coordenadas } \\
\text { PSAD } 56\end{array}$ & $\begin{array}{c}\text { Coordenadas } \\
\text { WGS } 84\end{array}$ & Nombre & Ubicación /Sector & Descripción \\
\hline 1. & $\begin{array}{l}820427 \mathrm{E} \\
0036333 \mathrm{~N}\end{array}$ & $\begin{array}{c}\text { 0820131E; } \\
\text { 0035961N; } \\
2297 \text { m.s.n.m }\end{array}$ & $\begin{array}{c}\text { Tola } \\
\text { EMAPA }\end{array}$ & $\begin{array}{l}\text { Al norte del cancha } \\
\text { de futbol de Caran- } \\
\text { qui, al final oeste de } \\
\text { la calle Los Incas }\end{array}$ & $\begin{array}{l}\text { Condición: parcialmente destruido. } \\
\text { Forma original: cuadrilateral. } \\
\text { Tamaño actual de la cima: } 46 \text { x } \\
46 \mathrm{~m} \text { x } 8.5 \mathrm{~m} \text { de altura; vestigios } \\
\text { de gradas en el lado oeste del } \\
\text { montículo. } \\
\text { Tiene monumentos de personas } \\
\text { históricas encima colocados en } \\
1963 \text {. }\end{array}$ \\
\hline 2. & $\begin{array}{l}820267 \mathrm{E} ; \\
0036366 \mathrm{~N}\end{array}$ & $\begin{array}{c}820009 \mathrm{E} ; \\
0035945 \mathrm{~N} \\
2285 \text { m.s.n.m. }\end{array}$ & $\begin{array}{c}\text { Tola } \\
\text { Carranco }\end{array}$ & $\begin{array}{l}\text { Al oeste de la Tola } \\
\text { EMAPA, en el lado } \\
\text { oeste de calle Juana } \\
\text { Atabalipa }\end{array}$ & $\begin{array}{l}\text { Condición: destruida. } \\
\text { Forma original: hemisférica. } \\
\text { c. } 100 \times 80 \mathrm{~m} \times 10-12 \mathrm{~m} \text { de altura. } \\
\text { Datos por fotos históricos y } \\
\text { memoria. }\end{array}$ \\
\hline 3. & $\begin{array}{l}820416 \mathrm{E} ; \\
0036164 \mathrm{~N}\end{array}$ & $\begin{array}{c}820101 \mathrm{E} ; \\
0035721 \mathrm{~N} \\
2310 \text { m.s.n.m. }\end{array}$ & $\begin{array}{c}\text { Tola } \\
\text { Centro-Sur }\end{array}$ & $\begin{array}{l}\text { En la esquina oeste } \\
\text { de la intersección } \\
\text { de las calles } \\
\text { Princesa Paccha y } \\
\text { Emperador Cacha }\end{array}$ & $\begin{array}{l}\text { Condición: destruida. } \\
\text { Datos de tradición oral. } \\
\text { Parecido a Tola Emapa en tamaño } \\
\text { según memoria. }\end{array}$ \\
\hline 4. & $\begin{array}{c}820400 \mathrm{E} \\
00366401 \mathrm{~N}\end{array}$ & $\begin{array}{c}820154 \mathrm{E} ; \\
0036041 \mathrm{~N} \\
2284 \text { m.s.n.m }\end{array}$ & $\begin{array}{c}\text { Tola } \\
\text { Vásquez } \\
\text { (Fonsalci) }\end{array}$ & $\begin{array}{l}\text { Inmediatamente al } \\
\text { norte } \\
\text { de la Tola } \\
\text { EMAPA }\end{array}$ & $\begin{array}{l}\text { Condición: intacto con evidencias } \\
\text { de excavación clandestina.Forma } \\
\text { original: hemisférica. }\end{array}$ \\
\hline 5. & $\begin{array}{l}820621 \mathrm{E} \\
0036275 \mathrm{~N}\end{array}$ & $\begin{array}{c}\text { 820363E; } \\
0035927 \mathrm{~N} \\
2310 \text { m.s.n.m. }\end{array}$ & $\begin{array}{c}\text { Tola } \\
\text { Sin Nombre }\end{array}$ & $\begin{array}{l}\text { A } 300 \text { m. al este de } \\
\text { la Tola EMAPA }\end{array}$ & $\begin{array}{l}\text { Condición: destruida } \\
\text { Forma original: probablemente } \\
\text { hemisférica } \\
\text { Datos por tradición oral. }\end{array}$ \\
\hline 6. & $\begin{array}{l}820115 \mathrm{E} \\
0036502 \mathrm{~N}\end{array}$ & $\begin{array}{c}819855 \mathrm{E} \\
0036126 \mathrm{~N} \\
2275 \text { m.s.n.m. }\end{array}$ & $\begin{array}{c}\text { Tola } \\
\text { Morejón }\end{array}$ & $\begin{array}{l}300 \text { metros al } \\
\text { noroeste de la Tola } \\
\text { EMAPA, en la } \\
\text { margen oriental de } \\
\text { la quebrada Cuzca }\end{array}$ & $\begin{array}{l}\text { Condición: destruida } \\
\text { Forma original: probablemente } \\
\text { hemisférica } \\
\text { Datos de historia oral. } \\
\text { Señor Vicente Guerrero, de } 74 \\
\text { años de edad, vecino de este sector, } \\
\text { indicó que la tola tenía } 50 \text { metros } \\
\text { de altura y } 300 \text { metros de lado. } \\
\text { Fotografías de vestigios }\end{array}$ \\
\hline
\end{tabular}




\begin{tabular}{|c|c|c|c|c|c|}
\hline 7. & $\begin{array}{l}820837 \mathrm{E} \\
0036203 \mathrm{~N}\end{array}$ & $\begin{array}{c}820595 \mathrm{E} \\
0035858 \mathrm{~N} \\
2320 \text { m.s.n.m }\end{array}$ & $\begin{array}{c}\text { Tola } \\
\text { La Playa } \\
\text { Madres } \\
\text { Mercedarias }\end{array}$ & $\begin{array}{l}\text { Tras el Coliseo } \\
\text { de las Madres } \\
\text { Mercedarias. Al } \\
\text { oeste de la Av. El } \\
\text { Retorno }\end{array}$ & $\begin{array}{l}\text { Condición: destruida. } \\
\text { Datos de memoria. }\end{array}$ \\
\hline 8. & & $\begin{array}{c}0820027 \mathrm{E} \\
0035600 \mathrm{~N} \\
2340 \text { m.s.n.m. }\end{array}$ & $\begin{array}{c}\text { Tola } \\
\text { Floralp Queso }\end{array}$ & $\begin{array}{l}\text { En el lado sur de } \\
\text { la calle Princesa } \\
\text { Paccha }\end{array}$ & $\begin{array}{l}\text { Condición: destruida. } \\
\text { Tradición oral. }\end{array}$ \\
\hline 9. & & $\begin{array}{c}820196 \mathrm{E} \\
0036088 \mathrm{~N} \\
2295 \text { m.s.n.m. }\end{array}$ & $\begin{array}{c}\text { Tola } \\
\text { Susana Merlo }\end{array}$ & $\begin{array}{l}\text { Al norte de Tola } \\
\text { Emapa }\end{array}$ & $\begin{array}{l}\text { Condición: destruida. } \\
\text { Forma original: probablemente } \\
\text { hemisférica } \\
\text { Datos de memoria. }\end{array}$ \\
\hline 10. & & $\begin{array}{c}819515 \mathrm{E} \\
0035749 \mathrm{~N} \\
2310 \text { m.s.m.n. }\end{array}$ & $\begin{array}{c}\text { Tola } \\
\text { Madres } \\
\text { Dominicas }\end{array}$ & $\begin{array}{l}\text { Atrás y al norte del } \\
\text { Monasterio de las } \\
\text { Madres Dominicas } \\
\text { en la calle Princesa } \\
\text { Paccha }\end{array}$ & $\begin{array}{l}\text { Condición: destruida. } \\
\text { Forma original: probablemente } \\
\text { hemisférica } \\
\text { Datos de memoria. } \\
\text { Destruida en los años } 50 \text { para } \\
\text { hacer ladrillos }\end{array}$ \\
\hline 11. & $\begin{array}{l}820827 \mathrm{E} \\
0035790 \mathrm{~N}\end{array}$ & $\begin{array}{c}820578 \mathrm{E} \\
0035445 \mathrm{~N} \\
2330 \text { m.s.m.n. }\end{array}$ & Tola Valencia & $\begin{array}{l}\text { Rafael Carranco } \\
\text { vendió el terreno a } \\
\text { Juan Valencia }\end{array}$ & $\begin{array}{l}\text { Condición: destruida. } \\
\text { Datos: fotos de vestigios y me- } \\
\text { moria. }\end{array}$ \\
\hline 12. & & $\begin{array}{c}819928 \mathrm{E} \\
0036088 \mathrm{~N} \\
2306 \text { m.s.n.m. }\end{array}$ & $\begin{array}{c}\text { Tola } \\
\text { Susy Aguirre }\end{array}$ & $\begin{array}{l}\text { Al lado norte de } \\
\text { la calle Princesa } \\
\text { Paccha }\end{array}$ & $\begin{array}{l}\text { Condición: destruida. } \\
\text { Forma original: probablemente } \\
\text { hemisférica } \\
\text { c. } 100 \text { x } 100 \mathrm{~m} \text { x } 20 \mathrm{~m} \text { de alto. } \\
\text { Datos de memoria. } \\
\text { Hallazgos de huesos humanos y } \\
\text { ollas. }\end{array}$ \\
\hline 13. & & $\begin{array}{c}820462 \mathrm{E} \\
0035840 \mathrm{~N} \\
2304 \text { m.s.n.m. }\end{array}$ & $\begin{array}{c}\text { Tola } \\
\text { Rueda-Gomez }\end{array}$ & $\begin{array}{l}\text { Terreno en el } \\
\text { cuadro NW de } \\
\text { la intersección de } \\
\text { calles Wiracocha y } \\
\text { Cory Cory }\end{array}$ & $\begin{array}{l}\text { Condición: destruida } \\
\text { Tradición oral. }\end{array}$ \\
\hline 14. & & $\begin{array}{l}0820428 \mathrm{E} \\
0035611 \mathrm{~N} \\
2315 \text { m.s.n.m. }\end{array}$ & $\begin{array}{c}\text { Tola } \\
\text { Davilos }\end{array}$ & $\begin{array}{l}\text { Inmediatamente } \\
\text { al sur del baño del } \\
\text { sitio de Incawasi }\end{array}$ & $\begin{array}{l}\text { Condición: destruida. } \\
\text { Tradición oral. }\end{array}$ \\
\hline 15. & & $\begin{array}{l}0820379 \mathrm{E} \\
0035462 \mathrm{~N} \\
2324 \text { m.s.n.m. }\end{array}$ & $\begin{array}{l}\text { Tola } \\
\text { M. Torres }\end{array}$ & $\begin{array}{l}\text { Abajo y al norte del } \\
\text { Cementerio en calle } \\
\text { La Huaca }\end{array}$ & $\begin{array}{l}\text { Condición: destruida. } \\
\text { Tradición oral. } \\
\text { Vestigios y horno de ladrillos. }\end{array}$ \\
\hline 16. & & $\begin{array}{c}0820314 \mathrm{E} \\
0035305 \mathrm{~N} \\
2345 \text { m.s.n.m. }\end{array}$ & $\begin{array}{l}\text { Tola } \\
\text { A. Jiménez }\end{array}$ & $\begin{array}{l}\text { Arriba y al suroeste } \\
\text { del Cementerio en } \\
\text { calle La Huaca }\end{array}$ & $\begin{array}{l}\text { Condición: destruida. } \\
\text { Vestigios y horno de ladrillos. }\end{array}$ \\
\hline 17. & $\begin{array}{l}821296 \mathrm{E} \\
0037658 \mathrm{~N}\end{array}$ & $\begin{array}{c}821027 \mathrm{E} \\
0037281 \mathrm{~N} \\
2242 \text { m.s.n.m. }\end{array}$ & $\begin{array}{l}\text { Tola } \\
\text { Cementerio } \\
\text { San Miguel }\end{array}$ & $\begin{array}{l}\text { Esquina noroeste } \\
\text { de Av. El Retorno } \\
\text { y Calle Ricardo } \\
\text { Sánchez, frente el } \\
\text { Coliseo Ramiro } \\
\text { Guzmán Rueda }\end{array}$ & $\begin{array}{l}\text { Cementerio actual San Miguel de } \\
\text { Ibarra. } \\
\text { Forma original: hemisférica. } \\
\text { c. } 100 \mathrm{~m} \text { en diámetro, y } 10 \mathrm{~m} \text { de } \\
\text { altura. } \\
\text { Condición: muy modificada de su } \\
\text { forma y actualmente cubierta de } \\
\text { tumbas modernas. }\end{array}$ \\
\hline
\end{tabular}




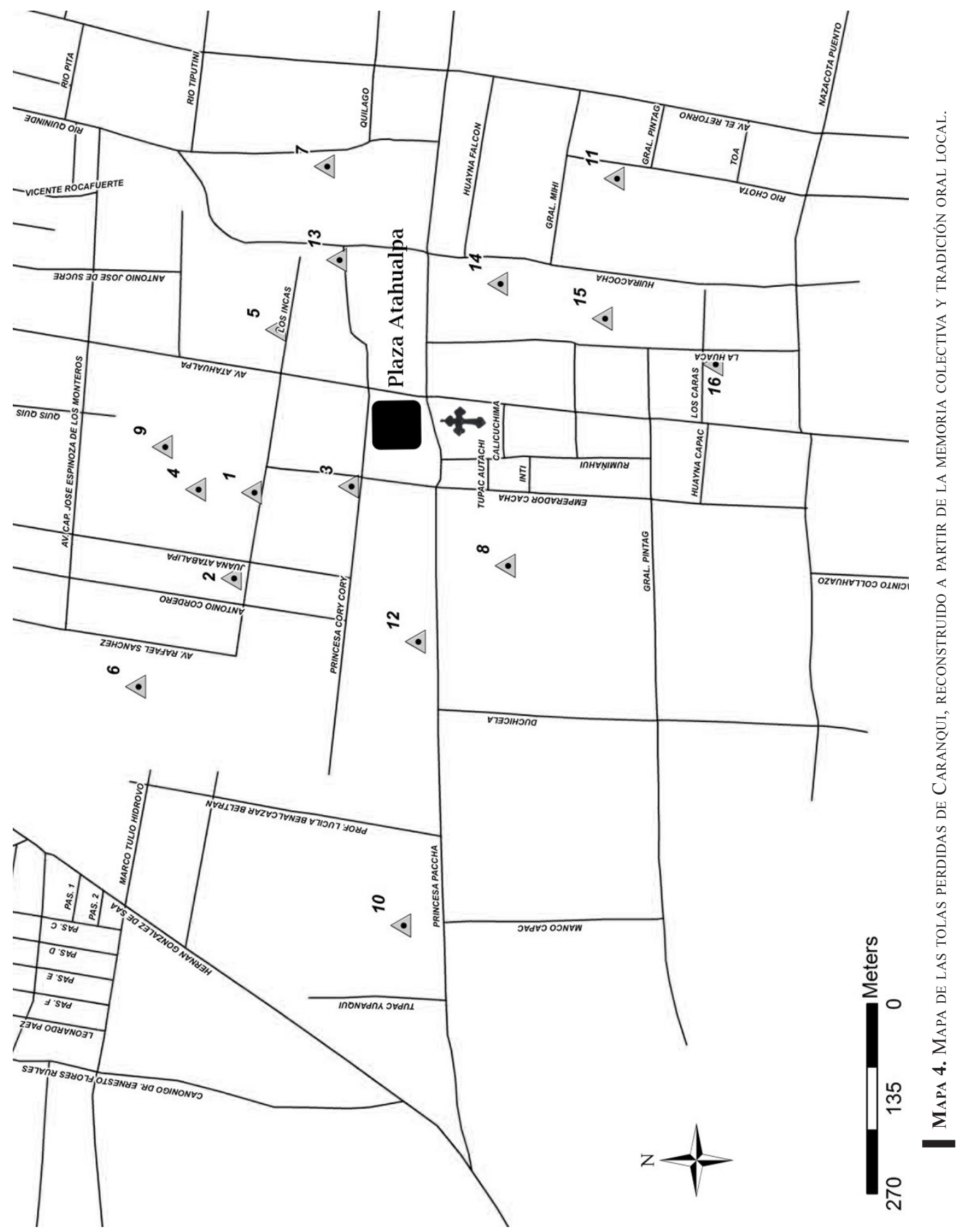


La significancia del sitio Caranqui es subrayada por los restos arqueológicos pertenecientes a viviendas y enterramientos cuyos fechados radiocarbónicos (Bray y Echeverría, 2010) indican su existencia hace 2000 años y también por la elección de este sitio por los incas para su centro administrativo hacia los principios del siglo XVI (Bray y Echeverría, 2014). Así la arqueología provee evidencia de una historia larga e ilustrada para la parroquia de Caranqui que amerita ser preservada para el conocimiento de las generaciones futuras. Por eso, insistimos una vez más en la importancia y necesidad de conservar los pocos montículos que quedan como monumentos a la capacidad física e intelectual de la gente aborigen de estas tierras los antepasados del País Caranqui. A fin de garantizar la conservación de los sitios y bienes patrimoniales arqueológicos, los gobiernos locales y provinciales deben poseer un comisario de patrimonio, para que permanentemente esté vigilando los sitios principales. Además, se deberá estimular de alguna manera a los propietarios de los terrenos donde se ubican bienes patrimoniales y sancionar conforme a la Ley a quienes dañen los bienes patrimoniales. Es importante que las instituciones, especialmente de cultura, de cada localidad, coordinen con el Instituto Nacional de Patrimonio Cultural, para preservar lo poco que nos queda, del otrora riquísimo patrimonio arqueológico del País Caranqui.

\section{Agradecimientos}

La finalización de este reporte fue posible, en parte, con el apoyo del Proyecto Prometeo de la Secretaría Nacional de Educación Superior, Ciencia y Tecnología (Senescyt) de la República del Ecuador; el GADM, Cantón Ibarra y la Universidad Técnica del Norte. Asimismo, estamos en deuda con los habitantes de Caranqui por su interés, apoyo y estímulo para nuestra investigación. Entre estos, quisiéramos reconocer especialmente varias personas quienes nos ayudaron en este proyecto por sus recuentos y memorias: Dra. Susana Aguirre, Sra. Amparo Aguirre, Dr. Gilberto Aguirre, Dr. Gonzalo Checa, Sra. Delia Espinosa, Sra. Inés Flores, Sr. Tobías Flores y Srta. Elena Flores, Sra. Matilde Rueda, Sra. Marianita Gómez, Sr. Miguel Gómez Rueda, Sr. Vicente Guerrero, Sr. Oswaldo Quintana, y Sra. Irma Tinajero. También ofrecemos nuestros agradecimientos a varios funcionarios del Municipio de Ibarra, especialmente Msc. Cristina Muñoz y Sr. Robert Arrunate, y el Ing. Pablo Ocaña por la producción del mapa con las tolas de Caranqui. Asimismo querríamos agradecer a Sr. Rafael. Agradecemos a Mathieu Flament por la traducción del resumen. 


\section{Bibliografía}

AHBC/I, 1604-1(7.IV) "Francisco Ramos, cacique de Carangue, vende a don Garcia Tulcanaza tierras en Conrraqui," 9 ff. 1308/250/4/M.

AHBC/I, Protocolos Notariales, 1624, fls. 83r-84r. 1624-3(7.V.) "Carta de venta de tierras que hace don Cristóbal de Carvajal, principal del pueblo de Carangue, a don Cristobal Quitumba, natural del pueblo de Tusa, en el Valle de Ambuqui."

AHBC/I, 1626-1 “Carta venta de Felipe Velásquez, principal de Carangue, y dona Cecila Farinquilago su mujer, a Maria yndia natural de Chuquin, de dos cuadras en el valle de Cotabo, donde estan algodonales, por el precio de veinte patacones de ocho reales," Protocolos Notariales, 1626, fls. 84r-85v. 47/7/1/J.

AHBC/I, 1642-1(29.X) "Venta de tierras en Ambuqui que hace don Mateo de la Torre a Lorenzo Tirrilla, indio," Protocolos Notariales, 1641 a 1645, fls. 284r-v. 57/19/0/J.

Anónimo de Quito, 1965 [1573], “La Cibdad de Sant Francisco del Quito”, en: Jiménez de la Espada, Marco (Ed.) Relaciones Geográficas de Indias, Ediciones Atlas, Madrid, pp. 205-232.

Athens, J. S. 2012, El Sitio Tola de la Hacienda Zuleta: Investigaciones 2010. Manuscrito archivado en el Instituto Nacional de Patrimonio Cultural, Quito.

2003, Inventory of Earthen Mound Sites, Northern Highland Ecuador, Manuscrito archivado en el Instituto Nacional de Patrimonio Cultural, Quito.

1999, "Volcanism and archaeology in the northern highlands of Ecuador", en: Mothes, Patricia (Ed.) Actividad Volcánica y Pueblos Precolombinos en el Ecuador, Abya-Yala, Quito.

1980, El proceso evolutivo de las sociedades complejas y la ocupación del Periodo Cara Tardio en los Andes Septentrionales del Ecuador, Colección Pendoneros N², Instituto Otavaleño de Antropología, Otavalo.

1978, Evolutionary Process in Complex Societies and the Late Period-Cara Occupation of Northern Highland Ecuador. Ph.D. dissertation, Department of Anthropology, University of New Mexico, University Microfilms, Ann Arbor.

Athens, J. S., \& Osborn, A. 1974, Prehistoric Earth Mounds in the Highlands of Ecuador: A Preliminary Report, Manuscrito archivado en el Instituto Otavaleño de Antropología, Otavalo, Ecuador.

Borchart de Moreno, C. 2004, El corregimiento de Otavalo: Territorio, población, y producción textil (15531808), Universidad de Otavalo, Otavalo.

Bray, T. L. 2008, "Chiefdoms of the Ecuadorian highlands", en: Silverman, Helaine y William Isbell (Eds.) Handbook of South American archaeology, Kluwer Academic Publishers, New York, pp. 527-543.

2003, Los efectos del imperio Incaico en la frontera septentrional: Una investigación arqueológica, Abya-Yala, Quito.

1995, "El conjunto cerámico del Pais Caranqui: Una interpretación funcional”, Revista Memorias, 5, Quito, pp. 33-52.

1992, "Archaeological Survey in Northern Highland Ecuador: Inca Imperialism and the Pais Caranqui”, en: World Archaeology, 24 (2), pp. 218-233.

Bray, T. L. y Echeverría, J., 2014, "The late imperial site of Inca-Caranqui, northern highland Ecuador: At the end of empire", en: Nawpa Pacha, 35 (2), pp. 176-199.

2010, Informe Anual para el Proyecto: "La Arquitectura de Poder: Investigaciones al sitio Imperial Tardio de Inca-Caranqui, Ibarra, Ecuador, Fase III”, Manuscrito archivado en el Instituto Nacional de Patrimonio Cultural, Quito, Ecuador.

Caillavet, C. 2000, Etnias del norte. Etnohistoria e historia de Ecuador, Casa de Velásquez, Instituto Francés de Estudios Andinos (IFEA), Abya-Yala, Quito.

1983, “Toponimia histórica, arqueología, y formas prehispánicas de agricultura en la región de Otavalo, Ecuador", en: Bulletin de l'Institut Francais d'Etudes Andines, 12 (3-4), pp. 1-21.

1982, “Caciques de Otavalo en el siglo XVI: Don Alonso Maldonado y su esposa”, en: Miscelánea Antropológica Ecuatoriana: Boletín de los Museos del Banco Central del Ecuador, 2, Quito, pp. 38-55.

1981, "Etnohistoria ecuatoriana: nuevos datos sobre el Otavalo prehispánico", en: Cultura: Revista del Banco Central, 11, Quito, pp. 109-127.

Cordero, M. A. 2009, El Cacicazgo Cayambi: Trayectoria hacia la Complejidad Social en los Andes Septentrionales, XX, Abya-Yala, Quito.

Currie, E. 2001, "A late period Caranqui chiefdom in the northern highlands of Ecuador: Archaeological investigations at Hacienda Zuleta”, en: Internet Archaeology 10, http://intarch.ac.uk/journal/issue10/currie_index.html 
Echeverría, J. 2009, Prospección arqueológica y aprovechamiento educativo turístico del sitio - tola "El Tablon”, Yahuarcocha, Ibarra, Imbabura, Ecuador, Manuscript on file, Instituto Nacional de Patrimonio Cultural, Quito.

2004, Las Sociedades Prehispánicas de la Sierra Norte del Ecuador. Una aproximación arqueológica y antropológica, XX, Colección Otavalo en la Historia, Serie I, Perspectiva Histórica, Volumen No 1, Imprenta Noción, Quito.

1995, "La cerámica como indicador cronológico en el Área Septentrional Andina Norte", en: Echeverría, J. y Uribe, M. V., Área Septentrional Andina Norte: Arqueología y Etnohistoria, XX, Colección Pendoneros № 8, Banco Central del Ecuador, Instituto Otavaleño de Antropología, Abya-Yala, Quito, pp. 253-316.

Echeverría, J. y Uribe, M. V. 1995 - Área Septentrional Andina Norte: Arqueología y Etnohistoria; Colección Pendoneros $\mathrm{N}^{\circ}$ 8, Banco Central del Ecuador, Instituto Otavaleño de Antropología, Ediciones Abya-Yala, Quito.

Espinoza Soriano, W. 1983, Los Cayambes y Carangues: Siglos XV-XVI. El testimonio de la Etnohistoria, Colección Pendoneros, Vol. 61, 62, Instituto Otavaleño de Antropología, Otavalo.

Gondard, P. y López, F. 1983, Inventario arqueológico preliminar de los Andes septentrionales del Ecuador, MAG, PRONAREG, ORSTOM, Banco Central del Ecuador, Quito.

González Suárez, F. 1908, Los aborígenes de Imbabura y del Carchi, La edición en Anales de la Universidad, T. XVI, (1902-03), Quito.

Guillaume-Gentil, N. 1998, "Patrones de asentamiento en el piedemonte andino, en la alta cuenca del río Guayas", Proyecto la Cadena- Quevedo-La Maná-Ecuador, en: Guinea, Mercedes et al. (Coord.) El Área Septentrional Andina. Arqueología y Etnohistoria, Biblioteca Abya-Yala, 59, Quito, pp. 149-196.

Jara, H. 2007, Tulipe y la cultura yumbo. Arqueología comprensiva del subtrópico quiteño, FONSAL, Quito.

Jijón y Caamaño, J. 1952 - Antropología prehispánica del Ecuador, La Prensa Católica, reimpreso por la PUCE, Quito [1997].

1920, "Nueva contribución al conocimiento de los aborígenes de la provincia de Imbabura", en: Boletín de la Sociedad Ecuatoriana de Estudios Históricos Americanos, 4 (10), pp. 1-120; (11), pp.183-244.

1914, Contribución al conocimiento de los aborígenes de la provincia de Imbabura, Blass y Cia., Madrid.

Knapp, G. 1992, Riego Precolonial y Tradicional en la Sierra Norte del Ecuador, Abya-Yala, Quito.

1991, Andean Ecology. Adaptive Dynamics in Ecuador. Westview Press, Dellplain Latin American Studies, Vol. $\mathrm{N}^{\circ} 27$, Westview Press, Boulder.

Larraín Barros, H. 1980, Demografía y asentamientos indígenas en la sierra norte del Ecuador en el siglo XVI, Colección Pendoneros $\mathrm{N}^{\mathrm{a}}$ 11, Instituto Otavaleño de Antropología, Otavalo.

Lippi, R. 1998, Una Exploración Arqueológica del Pichincha Occidental, Quito, Ecuador.

Lumbreras, L. 1990, Cronología Arqueológica de Cochasquí, Ecuador. Consejo Provincial de Pichincha, Quito.

Marcos, Jorge. 1988, Real Alto. La Historia de un centro ceremonial Valdivia, ESPOL y Corporación Editora Nacional, Quito.

Meyers, A. 1981, "Análisis de la cerámica de Cochasquí", en: Oberem, Udo (Ed.) Cochasquí: Estudios Arqueológicos, Colección Pendoneros, Instituto Otavaleño de Antropología, Otavalo, pp. 219-285.

Minc, L.et al. 2014, "Potting clays and ceramic provenance in northern highland Ecuador", en: de la Fuente, Guillermo y Emily, Stovel (Eds.) Avances en la Arqueometría Cerámica en Latinoamérica, British Archaeological Reports International, Oxford.

Moreno, S. 2007, Historia antiguo del Pais Imbaya, Centro de Investigaciones, Universidad de Otavalo, Otavalo.

Muñoz, C. y Bray, T. L. s/f, Informe de visita a Cochicaranqui, 2014, Archivado en el Gobierno Autónomo Municipal, Cantón Ibarra, Ecuador.

Meyers, A. 1981, “Análisis de la cerámica de Cochasqui”, en: Oberem, Udo (Ed.) Cochasquí: estudios arqueológicos, edited by, pp. 219-285. Colección Pendoneros, Instituto Otavaleño de Antropología, Otavalo, Ecuador.

Oberem, U. 1981a, "Algunas características arquitectónicas de las pirámides de Cochasquí", en: Oberem, Udo (Ed.) Cochasquí: Estudios Arqueológicos, Vol. 3, Colección Pendoneros, Instituto Otavaleño de Antropología, Otavalo, pp. 59-70.

1981b, Cochasquí: Estudios arqueológicos, 3 Volúmenes, Colección Pendoneros, № 3, 4, 5, Instituto Otavaleño de Antropología, Otavalo.

1978, "El acceso a recursos naturales de diferentes ecologías en la sierra ecuatoriana (siglo XVI)", en: Actes du XLII Congres Internacional des Americanistes, Congres Internacional des Americanistes, París, pp. 51-64. 
1969, "Informe provisional sobre algunas características arquitectónicas de las pirámides de Cochasquí/Ecuador", Amerikanistenkongr, 1, pp. 317-322.

Oberem, U., y Hartmann, R. 1981, “Informe de trabajo sobre las excavaciones arqueológicas de 1964-1965”, en: Oberem, Udo (Ed.) Cochasquí: Estudios Arqueológicos, Vol. 3, Colección Pendoneros; Instituto Otavaleño de Antropología, Otavalo, pp. 40-57.

Ontaneda, S. 1998, "Territorialidad en el Pais Caranqui: Aproximación a los linderos de las llactacuna", Cultura, Revista del Banco Central del Ecuador, 5, Quito, pp. 3-16.

Paris, J. 1924, Gramática de la Lengua Quichua actualmente en uso entre los indígenas del Ecuador. Cuenca, Taller de la Casa Editora El Progreso.

Paz Ponce De León, S. 1965 [1582], "Relación de los pueblos del partido de Otavalo", en: Jiménez De la Espada, Marco (Ed.) Relaciones Geográficas de Indias, tomo 2, Ediciones Atlas, Madrid, pp. 233-242.

Pazmiño, E. 2014, "Huataviro y los señoríos de la sierra norte del Ecuador", en: INPC, Revista del Patrimonio Cultural del Ecuador 5, Quito, pp. 56-71.

Porras, P. 1983, Arqueología del sitio Palenque, Los Ríos, La Ponga, Guayas, Artes Gráficas Señal, Quito.

1975, Fase Cosanga, Ediciones de la Universidad Católica, Quito.

1961, Contribución al Estudio de la Arqueología e Historia de los Valles Quijos y Misagualli (Alto Napo) en la Región Oriental del Ecuador, Editorial Fénix, Quito.

Ramon, G. 1987 - La Resistencia Andina, Cayambe 1500-1800, Centro Andino de Acción Popular, Quito.

Salomon, F. 1990, "La política vertical en las fronteras del Tawantinsuyo", en: Revista Memoria, 1(1), MARKA; Quito, pp. 6-41.

1986, Native Lords of Quito in the Age of the Incas. Cambridge University Press, New York.

1980, Los Señores Étnicos de Quito en la Epoca de los Incas, Serie Etnohistoria, Colección Pendoneros, Instituto Otavaleño de Antropologia, Otavalo, Ecuador.

Uhle, M. 1927, Estudios Esmeraldeños, Anales de la Universidad Central, Vol. 29, № 262, Quito.

Valdez, F. 1987, Proyecto Arqueológico La Tolita (1983-1986), Banco Central, Quito.

Wurster, W. 1981, "Aportes a la reconstrucción de edificios con planta circular sobre las pirámides con rampa de Cochasquí”, en: Oberem, Udo, (Ed.) Cochasqui: Estudios Arqueológicos, Colección Pendoneros, Instituto Otavaleño de Antropología, Otavalo, pp. 79-124.

Yanchar, K. 2013, Degree and Scale of Interactions among Chiefdoms during the Pre-Hispanic Late Period in Northern Highland Ecuador (AD 1250-1525). Master's Thesis, Oregon State University, Corvallis, Oregon. 
